\title{
Video Article \\ Methods for Image-based Surveys of Benthic Macroinvertebrates and Their Habitat Exemplified by the Drop Camera Survey for the Atlantic Sea Scallop
}

\author{
N. David Bethoney ${ }^{1}$, Kevin D. E. Stokesbury ${ }^{1}$ \\ ${ }^{1}$ School for Marine Science and Technology, University of Massachusetts Dartmouth \\ Correspondence to: N. David Bethoney at nbethoney@umassd.edu
}

URL: https://www.jove.com/video/57493

DOI: doi:10.3791/57493

Keywords: Environmental Sciences, Issue 137, Environmental Sciences, Marine Ecology, Fisheries, Placopecten magellanicus, Cooperative Research, Resource Management, Underwater imaging

Date Published: $7 / 2 / 2018$

Citation: Bethoney, N.D., Stokesbury, K.D. Methods for Image-based Surveys of Benthic Macroinvertebrates and Their Habitat Exemplified by the Drop Camera Survey for the Atlantic Sea Scallop. J. Vis. Exp. (137), e57493, doi:10.3791/57493 (2018).

\section{Abstract}

Underwater imaging has long been used in the field of marine ecology but decreasing costs of high-resolution cameras and data storage have made the approach more practical than in the past. Image-based surveys allow for initial samples to be revisited and are non-invasive compared to traditional survey methods that typically involve nets or dredges. Protocols for image-based surveys can vary greatly but should be driven by target species behavior and survey objectives. To demonstrate this, we describe our most recent methods for an Atlantic sea scallop (Placopecten magellanicus) drop camera survey to provide a procedural example and representative results. The procedure is divided into three critical steps that include survey design, data collection, and data products. The influence of scallop behavior and the survey goal of providing an independent assessment of the U.S. sea scallop resource on the survey procedure are then discussed in the context of generalizing the method. Overall, the broad applicability and flexibility of the University of Massachusetts Dartmouth School for Marine Science and Technology (SMAST) drop camera survey demonstrates the method could be generalized and applied to a variety of sessile invertebrates or habitat focused research.

\section{Video Link}

The video component of this article can be found at https://www.jove.com/video/57493/

\section{Introduction}

The Atlantic sea scallop (Placopecten magellanicus) is a marine bivalve mollusk distributed throughout the continental shelf of the northwestern Atlantic Ocean from the Gulf of the St. Lawrence, Canada to Cape Hatteras, North Carolina ${ }^{1}$. The sea scallop fishery in the United States has experienced unprecedented increases in landings and value over the past fifteen years and has become one of the country's highest valued fisheries with landings worth approximately $\$ 440$ million in $2015^{2}$. Despite this increase, scallop fishing effort has been substantially reduced over the past 20 years through the implementation of an area rotation system that aims to protect areas with juvenile scallops and focus fishing in areas with larger scallops in high densities ${ }^{1}$. This management approach requires spatially-specific information on scallop density and size, which is provided by several surveys including the University of Massachusetts Dartmouth School for Marine Science and Technology (SMAST) drop camera survey.

The goal of the SMAST drop camera survey is to provide fishery resource managers, marine scientists and fishing communities with an independent assessment of the U.S. sea scallop resource and its associated habitat. The survey was developed collaboratively with scallop fishermen and applies quadrat sampling techniques based on diving studies ${ }^{3,4}$. Initial surveys in the early 2000 s focused on estimating the density of sea scallops within closed portions of a productive area of the fishery known as Georges Bank ${ }^{5}$, but the survey expanded to cover the majority of the scallop resource in U.S. and Canadian waters $\left(\approx 100,000 \mathrm{~km}^{2}\right)^{6,7}$. Information from the survey has been incorporated into the scallop stock assessment through the Stock Assessment Workshop process and reliably provided to the New England Fisheries Management Council to aid in annual scallop harvest allocation ${ }^{8}$. In addition, data from the SMAST drop camera survey has contributed in numerous ways to understanding the ecology of non-scallop species ${ }^{7,9,10,11,12}$ and the characterization of benthic habitat ${ }^{13,14,15}$. This broad applicability demonstrates the method could be generalized and applied to a variety of sessile invertebrates, potentially helping to alleviate the problem of the expansion of invertebrate fisheries outpacing the scientific knowledge and policy needed to successfully manage them ${ }^{16}$. Further, image-based sampling is non-invasive compared to traditional population sampling methods and increasingly affordable due to decreasing costs of highresolution cameras and data storage ${ }^{17,18}$. Here the 2017 methods of the SMAST drop camera survey used for scallop management on the U.S portion of Georges Bank are presented to exemplify the procedure. We discuss the rationale behind this procedure to aid in its generalization and application to other sessile invertebrates. 


\section{Protocol}

\section{Survey Design}

1. Find one or more off-shore commercial scallop vessels available for 6 - 8-day intervals.

2. Construct a steel pyramid with an interior frame where three cameras, lights, and a junction box for a fiber optic cable can be mounted (Figure 1). Ensure that one camera is a high resolution digital still camera and two are lower resolution, but still high definition, video cameras.

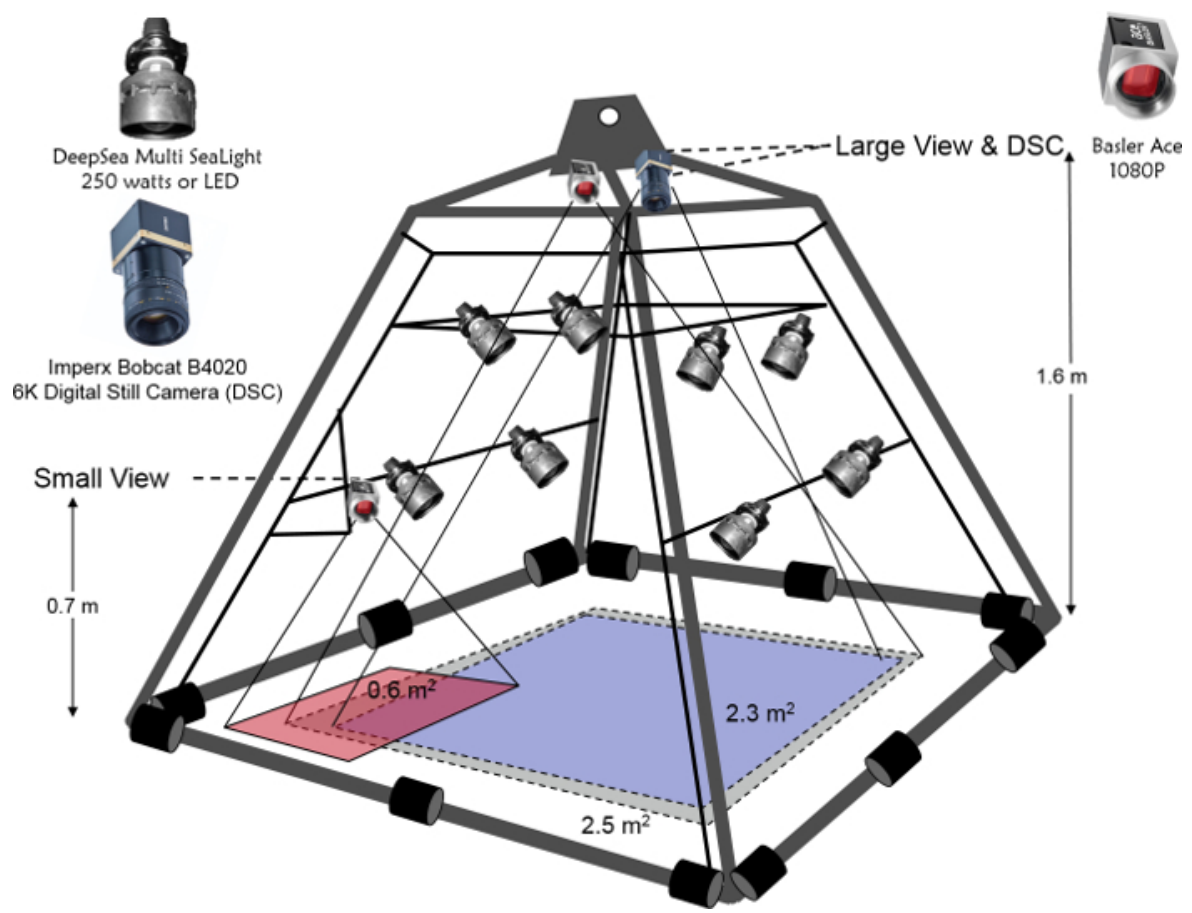

Figure 1: Drop camera survey pyramid with cameras and lights used for data collection in 2017. The University of Massachusetts Dartmouth, School for Marine Science and Technology drop camera survey pyramid with cameras and lights used for data collection in 2017. A junction box that connects camera and light cables to a fiber optic cable is mounted between the two bars with lights and is not shown. Please click here to view a larger version of this figure.

3. Use a systematic sampling design to place survey stations $5.6 \mathrm{~km}$ apart in most areas of Georges Bank utilized by the fishery and $2.8 \mathrm{~km}$ apart in two areas of importance

NOTE: Two scientists, a captain, and a mate were able to survey about 50 stations every 24 hours on the $5.6 \mathrm{~km}$ grid and 80 stations on the $2.8 \mathrm{~km}$ grid. Therefore, approximately 5 survey trips were needed to complete the survey.

\section{Data Collection}

1. Load equipment onto the vessel.

2. Set up equipment on the vessel deck.

1. Arrange pyramid, a pressure sensitive winch with fiber optic cable on a drum and attached to slip ring, and davit on to the deck of the vessel. Ensure that the fiber optic cable can run from the winch through the davit and to the pyramid without touching the vessel's winch cable.

2. Use small, temporary welds to affix winch, davit, and davit plate into place.

3. Wire pressure sensitive winch power cable into the vessel's fuse box.

4. Attach junction box to pyramid.

5. Attach cameras and lights to the pyramid.

6. Connect cameras and lights to the junction box with camera and light cables.

7. Run fiber optic cable through sheave and attach to davit.

8. Attach vessel hydraulic winch cable to pyramid.

3. Set up equipment in vessel wheelhouse.

1. Plug in and secure desktop computer.

2. Connect 2 monitors to the desktop computer. Secure one monitor near the computer and the second near the controls for the vessel's hydraulic winch.

3. Connect a global positioning system (GPS) device to the desktop computer via a USB port. 
4. Plug in and secure a laptop computer with a mobile field mapping program near the vessel helm. Load the station locations into the computer prior to departure.

5. Connect a GPS device to laptop computer via a serial port.

6. Connect cameras and lights to the vessel wheelhouse.

1. Attach the "deck end" of the wheelhouse run of fiber optic cable to optical slip ring on the pressure sensitive winch.

2. Attach the "wheelhouse end" of wheelhouse run of fiber optical cable to the fiber optic interface on the desktop computer and the light power plug.

3. Launch the field data collection program from the desktop computer. Ensure that all cameras mounted on the pyramid and plugged into the junction box automatically show as connected. NOTE: If all cameras do not show as connected, reset camera connections within the program or troubleshoot by swapping components (camera, connecting cables, slip ring, etc.) in a systematic manner.

4. Capture images and record data at each station.

1. Launch the mobile field mapping program from the laptop computer.

2. Select the "mark" tool and drag the target icon onto a station to provide a bearing to the station.

3. Slowly lower the sampling pyramid to the seafloor using vessel's hydraulic winch when the station has been reached and the vessel has been stopped.

NOTE: This is done by the vessel's crew and the pressure sensitive winch must be turned on prior to lowering the sampling pyramid.

4. Launch the field data collection program from the desktop computer while the pyramid is being lowered to the seafloor.

1. Double click "Area Short Name" box and enter a name for the area. NOTE: This only needs to be done for the first station of an area.

2. Click the "Launch Captains Cam" button to display the camera views and other information on the monitor near the hydraulic winch controls.

5. Switch on power to lights.

6. Capture quadrat data once the sampling pyramid has landed on the seafloor.

1. In the field data collection program, click "Start Station" to start the recording of video. NOTE: The button will blink red while the video is recording.

2. Click "Take Snapshots" when a clear view of the seafloor appears, then click "Save All" to capture a still image from all camera views simultaneously.

3. Click the "Write to Database" button.

NOTE: This will bring up a new dialogue box with depth, location, temperature, station number, quadrat number, area name, and a unique identification number automatically entered by the software.

4. Enter the number of scallops seen in the digital still camera image in the "Scallop Count" box and type any comments into the "Comments" box.

5. Click the "Submit Data" button to write the data about the quadrat as a row into the field database.

7. Lift the pyramid, until the seafloor can no longer be seen.

8. Slowly lower the pyramid to the seafloor and repeat steps 2.4.6 and 2.4.7. until data for four quadrats has been captured. Ensure that the pyramid has drifted so that different quadrat images of the seafloor are captured.

9. Raise the sampling pyramid from the seafloor to a secure position next to the vessel.

10. End the station while the pyramid is being raised.

1. Click "End Station" in the field data collection program to end the video recording and advance program to the next station.

2. Click the "Quit Program" button to close the program.

3. Turn off power to lights.

4. Click "Capture Station" in the mobile field mapping program to mark the station as completed then repeat step 2.4.2.

11. Repeat previous steps of section 2.4. until all survey stations have been completed.

5. Conduct a camera calibration drop.

1. Measure the length of at least 30 grid cells of a wire grid with electronic calipers. Mark the cells that are measured.

2. Attach the grid to the base of sampling pyramid using twine or rope. Ensure that the measured grid cells are in the camera views.

3. Repeat steps 2.4.3 to 2.4.6.2 to capture images of the grid.

NOTE: This calibration is usually done before the first station but can be done prior to departure in a test tank or at any time during the survey. The purpose is to determine the length in $\mathrm{mm}$ to pixel ratio for confirming quadrat size and measuring features within the images.

6. Quantify data within digital still camera quadrat images.

NOTE: Use images from the other cameras and the video as aids in this process.

1. Launch the lab data collection program and select the "Digitize" profile.

2. From the dropdown menu, select the year, area, camera, station, and quadrat of interest.

3. Click "go" to bring an image based on the criteria selected in step 2.6.2. into the program.

4. In the "Substrate" section, click the boxes for the substrate types that are present. See ${ }^{14}$ for a detailed description of substrate types and how they are classified.

5. Quantify macrobenthic animals.

NOTE: 50 taxa of macrobenthos are counted or noted as present or absent. A complete list of these taxa and how they are tracked can be found in reference ${ }^{13}$.

1. Click the boxes for the animals that are present in the "Inverts" presence section.

2. Enter the number of each animal observed in the "Inverts" count section.

3. Click the red "SC" button and dot each scallop in the image. 
4. Click the green "SF" button and dot each sea star in the image.

5. Click the black "CL" button and dot each clapper (scallop that has died, but both sides of the shell are still attached to hinge) in the image.

6. Click the blue "Fl" button and dot each fish in the image.

7. In the "Fish" count section, enter the number of each fish type observed. NOTE: For the other dotted animals the program automatically counts the number of dots and assigns the counts to the appropriate category. For fish, dots are automatically counted, but the user must identify which type of fish and how many. The total number of fish dots counted by the program must match the number of each fish type entered by the user.

6. Click the "submit" button to write the data about the image as a row into the lab database and create a copy of the image with the animals dotted.

7. Perform a quality control of steps 2.6.4. and 2.6.5.

1. Change the profile in the lab data collection program to "ImageCheck." NOTE: This should be done by a different person from the one that completed steps 2.6 .4 and 2.6.5 for the image.

2. Repeat steps 2.6.2 and 2.6.3. to load the original image, dotted image, and fill in substrate and animal data entered by the "Digitize" user profile.

3. Review entry for accuracy and make any changes necessary.

4. Select the "submit" button to overwrite the data about the image submitted by the "Digitize" user and mark the image as quality controlled in the lab database.

8. Measure scallops observed in images.

NOTE: Scallops partially visible (obscured by growths, partly in image, etc.) or off the sea floor should not be measured.

1. Launch the image annotator program.

2. Select "File" and then "Load Image Directory" from the drop-down menu. Navigate to the dotted image of interest and load the image into the program.

3. Select the "line annotation" and draw a line from the umbo of scallop to the top of scallop shell.

4. Repeat step 2.6.8.3. for all measurable scallops in the image.

5. Select "File" and then "Save Annotations" to create a spread sheet of measurements.

6. Convert measurements from pixels to millimeters by using the average pixels to millimeters ratio from 2.5 .

\section{Data Products}

1. Calculate spatially specific estimates of scallop density and size.

1. Plot survey stations using mapping software.

2. Partition survey stations by Scallop Area Management Simulator (SAMS) model zones.

NOTE: In the U.S. Atlantic sea scallop fishery, the SAMS model is used to project sea scallop abundance and landings ${ }^{8}$. All of the following steps are done for each SAMS zone.

3. Average scallop measurements to obtain the average shell height of scallops.

4. Calculate mean densities and standard errors of scallops.

1. Increase the quadrat size by the average shell height of scallops in the SAMS zone to adjust for partially visible scallops counted along the edge of the image ${ }^{19}$.

2. Calculate density using the adjusted quadrat size and equations for a 2-stage sampling design to account for multiple quadrats being sampled at each station ${ }^{20}$ :

$$
\begin{aligned}
& \bar{x}_{i}=\sum_{j=1}^{n}\left(\frac{x_{i j}}{m}\right) \\
& =\bar{x}=\sum_{i=1}^{n}\left(\frac{\bar{x}_{i}}{n}\right)
\end{aligned}
$$

where $\mathrm{n}=$ primary sample units (stations), $\mathrm{m}=$ elements per primary sample unit (quadrats), $x_{i j}=$ measured value (counts of scallops) for element $\mathrm{j}$ in primary unit $\mathrm{i}, \bar{x}_{i}=$ sample mean per element (quadrat) in primary unit $\mathrm{i}$ (stations), and $\bar{x}=$ the mean over the two-stages. The standard error of this mean is:

$$
S . E .(\bar{x})=\sqrt{\frac{1}{n}\left(s^{2}\right)}
$$

where $s^{2}=\sum^{n}\left(\bar{x}_{i}-\bar{x}\right)^{2} /(n-1)$ is the variance among primary unit (stations) means.

2. Calculate total and exploitable biomass.

1. Multiply scallop density by the total area surveyed to estimate the number of scallops in the area.

2. Create a shell height frequency distribution of scallop measurements with $5 \mathrm{~mm}$ size bins.

3. Multiply 3.2.1. by the frequency of scallops in each size bin from 3.2.2. to get the number of scallops in each size bin in the area. 
4. Multiply the estimated meat weight of scallops at the mid-point of each $5 \mathrm{~mm}$ size bin by the number of scallops in each size bin. Use the shell height to meat weight regressions specified by the New England Fisheries Management Council's Scallop Plan Development Team to estimate the scallop weight at the size in grams ${ }^{21}$.

5. Sum the meat weight of scallops from 3.2.4. to produce an estimate of total scallop biomass. Convert scallop biomass from grams to metric tons.

6. Divide the sum of scallop meat weights from 3.2.5. by the total number of scallops from 3.2.1. to get the average weight of one scallop.

7. Multiply the number of scallops at each size bin from 3.2.3. by a commercial scallop dredge selectivity equation to estimate the number of exploitable scallops ${ }^{22}$.

8. Repeat steps 3.2.5. and 3.2.6. with the counts of exploitable scallops from 3.2.7. to estimate the biomass of scallops of exploitable size and their average meat weight.

3. Create scallop distribution maps.

1. Divide the sum of scallop counts, scallops with shell heights less than $75 \mathrm{~mm}$, and scallops with shell heights over $100 \mathrm{~mm}$ at each survey station by the total area viewed in the digital still camera $\left(9.2 \mathrm{~m}^{2}\right)$ at each station to respectively calculate overall scallop, juvenile scallop, and exploitable scallop density at each station.

2. Plot each density for each station to map the spatial distribution of overall, juvenile, and exploitable scallop abundance, respectively.

\section{Representative Results}

Survey stations were sampled as part of five research trips conducted from late April to mid-July (Figure 2). Due to visibility and weather issues, a swath of stations in SAMS zone CL2-S-EXT were not sampled and some stations in other zones were also dropped during quality assurance checks. For all other stations, four high quality digital still images were captured (Figure 3). For all images in these stations, substrate and macrobenthic animals were quantified and scallops were measured. Scallop counts and measurements were partitioned by SAMS zone allowing for abundance, distribution and biomass estimates, along with audited raw data of scallop counts and measurements, to be provided to the Northeast Fisheries Science Center and New England Fisheries Management Council by August 1 for inclusion into the annual scallop allocation process (Tables 1 and 2). Scallop distribution maps were created for all scallops, juvenile scallops (shell heights less than $75 \mathrm{~mm}$ ), and scallops of exploitable size (shell heights greater than $100 \mathrm{~mm}$ ) (Figure 4).

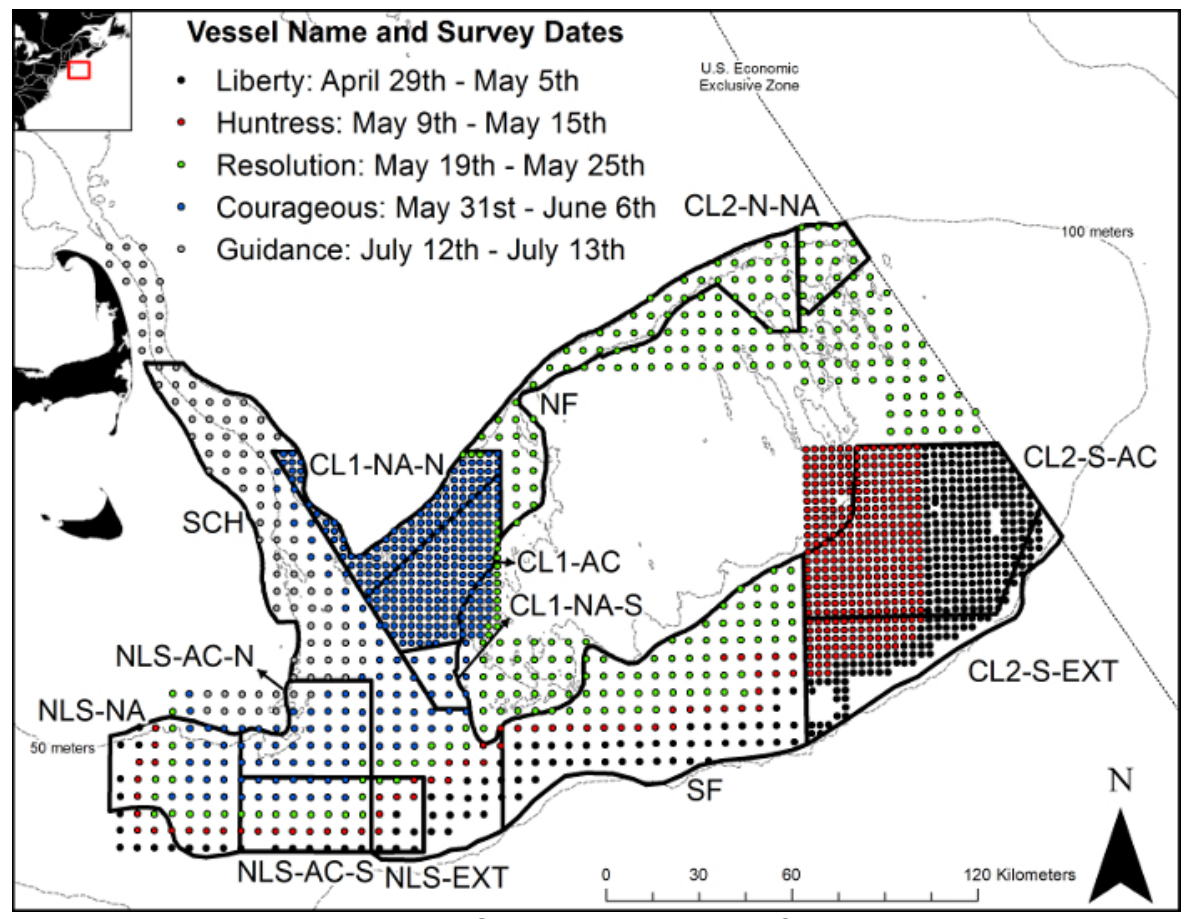

Figure 2: Drop camera stations on Georges Bank in 2017. Stations are displayed by the vessel with survey dates and stratified with areas of high interest sampled with stations $2.8 \mathrm{~km}$ apart and all other areas sampled with stations $5.6 \mathrm{~km}$ apart. Black lines and labels identify Scallop Area Management Simulator model zones used to project sea scallop abundance and landings. Please click here to view a larger version of this figure. 


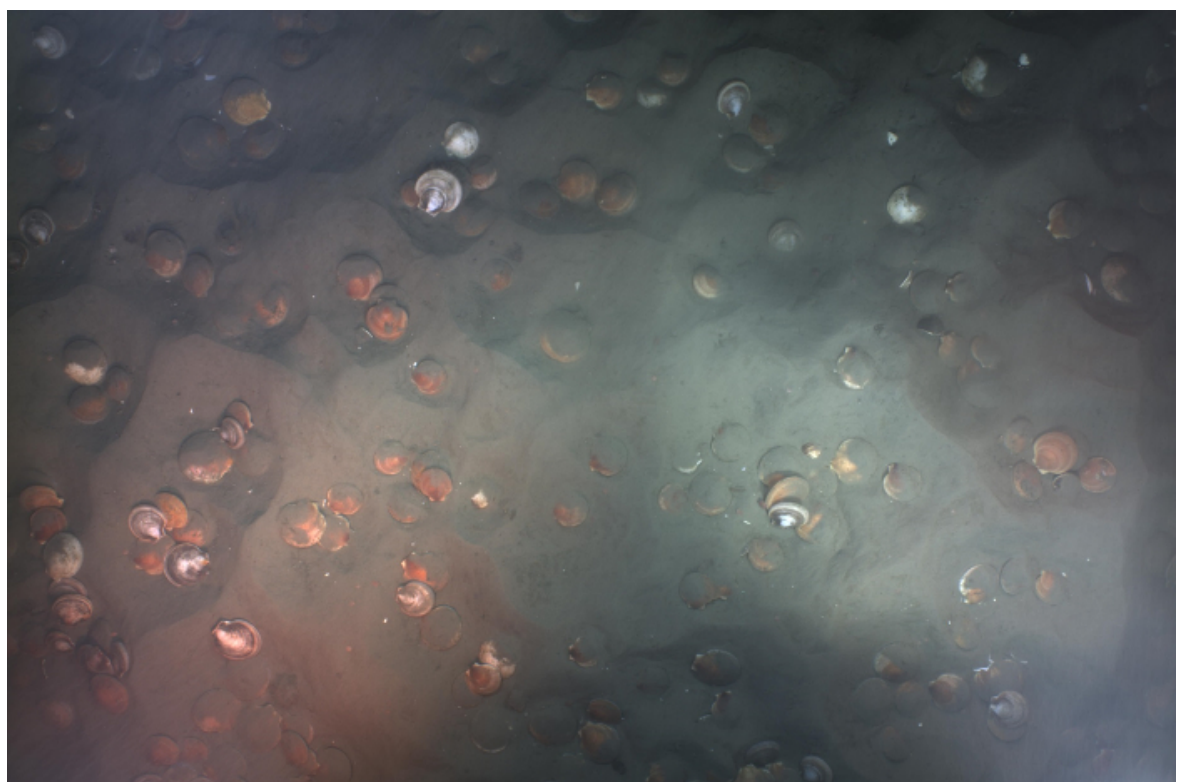

Figure 3: Example digital still image from the 2017 drop camera survey on Georges Bank. For the entire Georges Bank survey, substrate and macrobenthic animals were quantified and scallops were measured in 5,216 images of similar quality. All images can be viewed at $<\mathrm{http}: / /$ bit.ly/scallopsurvey>. Please click here to view a larger version of this figure.

\begin{tabular}{|c|c|c|c|c|c|c|c|}
\hline Area & Quad & Stations & Measured & $\mathrm{SH}$ & Sc. Per $\mathrm{m}^{2}$ & SE & Scallops \\
\hline CL1-NA-N & 2.6 & 101 & 858 & 105 & 0.98 & 0.29 & 761 \\
\hline CL1-AC & 2.6 & 155 & 81 & 106 & 0.06 & 0.01 & 66 \\
\hline CL1-NA-S & -- & 7 & 0 & -- & $<0.02$ & -- & -- \\
\hline CL2-N-NA & 2.6 & 16 & 58 & 87 & 0.43 & 0.2 & 214 \\
\hline CL2-S-AC & 2.6 & 435 & 556 & 93.6 & 0.14 & 0.01 & 465 \\
\hline CL2-S-EXT & 2.5 & 147 & 660 & 77.6 & 0.48 & 0.04 & 545 \\
\hline NF & 2.6 & 54 & 13 & 88 & 0.02 & 0.01 & 39 \\
\hline NLS-AC-N & 2.7 & 31 & 72 & 120 & 0.27 & 0.1 & 260 \\
\hline NLS-AC-S & 2.5 & 39 & 2,718 & 72.7 & 9.7 & 3.09 & 11,676 \\
\hline NLS-EXT & 2.6 & 14 & 170 & 95.1 & 2.24 & 2.16 & 966 \\
\hline NLS-NA & 2.6 & 42 & 696 & 99.1 & 2 & 0.83 & 2,597 \\
\hline $\mathrm{SCH}$ & 2.5 & 137 & 138 & 71.3 & 0.15 & 0.03 & 631 \\
\hline SF & 2.5 & 126 & 219 & 74.4 & 0.19 & 0.03 & 747 \\
\hline
\end{tabular}

Table 1: Digital still camera data from the 2017 drop camera survey of Georges Bank. Results are presented by Scallop Area Management Simulator model zones. Included in the table is the adjusted quadrat area (Quad), the number of stations sampled (Stations), the number of scallop shell heights measured (Measured), the mean shell height of scallops observed in $\mathrm{mm}(\mathrm{SH})$, the mean number of scallops per $\mathrm{m}^{2}$ (Sc. Per $\mathrm{m}^{2}$ ) with associated standard error (SE), and an estimate of the number of scallops in millions (Scallops). Results for CL1-NA-S could not be produced because no scallops were observed. 


\begin{tabular}{|c|c|c|c|c|c|c|}
\hline \multirow[b]{2}{*}{ Area } & \multicolumn{3}{|c|}{ Estimation of Total Biomass } & \multicolumn{3}{|c|}{ Estimation of Exploitable Biomass } \\
\hline & MW & MT & SE & MW & MT & SE \\
\hline CL1-NA-N & 18.28 & 13,900 & 4,100 & 23.85 & 9,900 & 2,950 \\
\hline CL1-AC & 24.87 & 1,650 & 350 & 33.72 & 1,350 & 300 \\
\hline CL1-NA-S & -- & -- & -- & -- & -- & -- \\
\hline CL2-N-NA & 14.89 & 3,200 & 1,500 & 26.51 & 2,100 & 980 \\
\hline CL2-S-AC & 15.84 & 7,360 & 685 & 23.47 & 4,600 & 425 \\
\hline CL2-S-EXT & 9.46 & 5,150 & 440 & 17.1 & 1,900 & 165 \\
\hline NF & 16.26 & 600 & 260 & 27.59 & 500 & 200 \\
\hline NLS-AC-N & 34.15 & 8,900 & 3,390 & 38.02 & 7,800 & 2,990 \\
\hline NLS-AC-S & 8.49 & 99,100 & 31,590 & 16.88 & 24,600 & 7,830 \\
\hline NLS-EXT & 16.73 & 16,200 & 15,590 & 19.54 & 7,600 & 7,310 \\
\hline NLS-NA & 20.4 & 53,000 & 22,100 & 25.13 & 30,700 & 12,800 \\
\hline $\mathrm{SCH}$ & 10.45 & 6,600 & 1,260 & 24.65 & 3,300 & 620 \\
\hline SF & 9.1 & 6,800 & 1,080 & 17.33 & 2,400 & 380 \\
\hline
\end{tabular}

Table 2: Estimates of total and exploitable biomass for the 2017 Georges Bank drop camera survey. Results are presented by Scallop Area Management Simulator model areas. Included in the table are the mean scallop meat weight in $\mathrm{g}(\mathrm{MW})$, the total weight of scallops in metric tons (MT) and the standard error in metric tons. Results for CL1-NA-S could not be produced because no scallops were observed. 


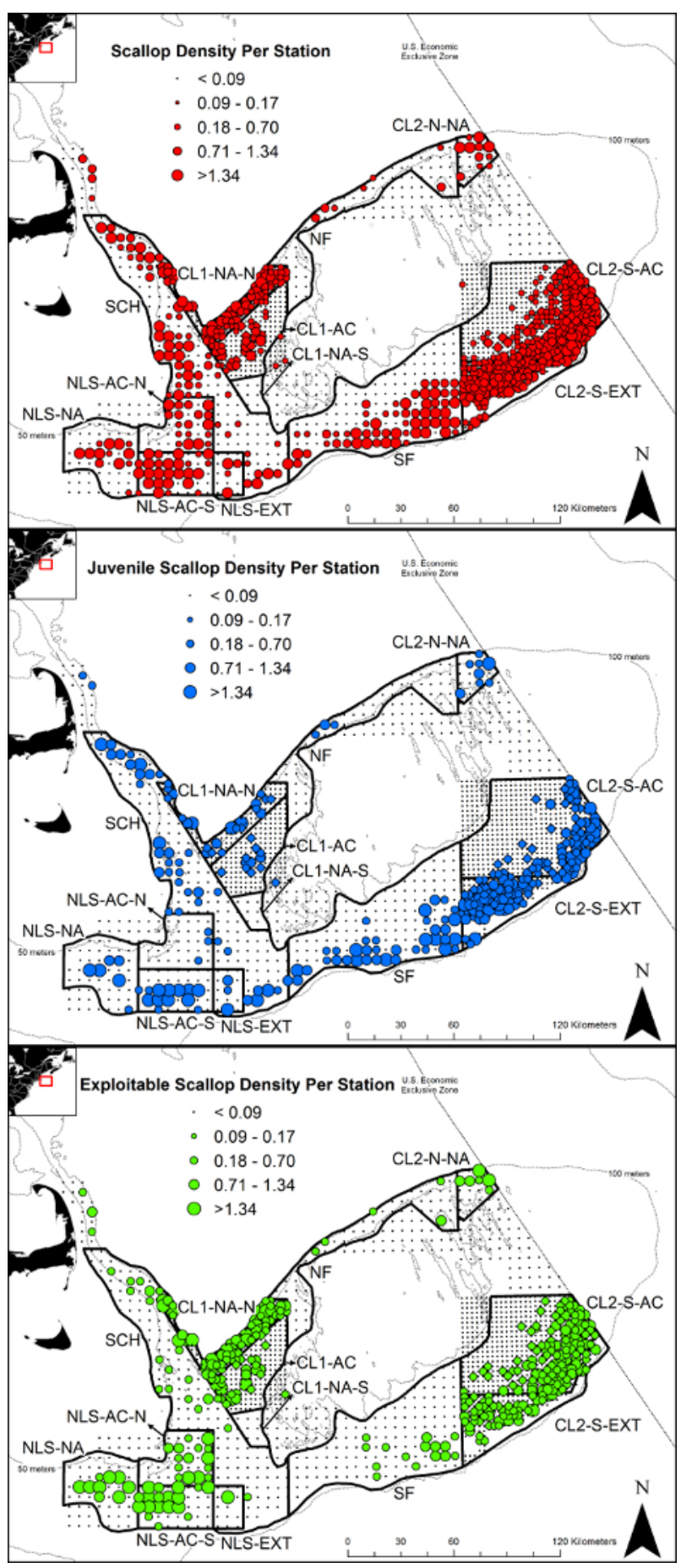

Figure 4: Scallop distribution and abundance on Georges Bank during 2017. Scallop distribution and abundance on Georges Bank during 2017 for all scallops (top), scallops less than $75 \mathrm{~mm}$ shell height (middle), and scallops greater than $100 \mathrm{~mm}$ shell height (bottom) from a drop camera survey. Please click here to view a larger version of this figure.

\section{Discussion}

The survey design protocols are flexible, but it is critical to consider the target species behavior and survey objectives when generalizing these protocols. Literature review and preliminary or initial studies can be used to incorporate target species behavior into survey design. For example, less than one scallop in $12.5 \mathrm{~m}^{2}\left(0.08 \mathrm{scallops} / \mathrm{m}^{2}\right)$ is below sustainable commercial fishing density ${ }^{23}$. Thus, by sampling four quadrats per station, the station sample area is linked to detecting scallops at commercial density. Additionally, sea scallops are usually aggregated rather than randomly distributed on the sea floor, influencing how station spacing impacts the precision of density estimates ${ }^{24}$. Several studies using mean and variance data from initial studies examined precision and determine that $5.6 \mathrm{~km}$ was the maximum distance stations should be placed apart ${ }^{5,25,26}$. The systemic sampling design of the survey was influenced by survey objectives. The boundaries of the SAMS zones change frequently and often after surveys have been conducted ${ }^{21,27}$. Systemic sampling avoids the serious problem of post-stratification of boundaries 
for spatial estimates that impacts randomly stratified or optimally allocated survey designs ${ }^{20}$. Uniform allocation of stations also facilitates detection of new scallop recruitment and mapping sea floor sediments and macroinvertebrate distributions ${ }^{28}$. The one step where it may not be possible to consider target species behavior and survey objectives is the identification of a survey vessel, which is why the protocol begins with this step. A vessel is essential to at-sea sampling and dictates subsequent steps of the survey design. For our protocols, it was vital to engage the commercial fishing industry to foster transparency in survey methods and confidence in survey results. Using commercial fishing vessels was an impactful way to include industry in our methods and the size and capabilities of the vessels allowed for a large, heavy camera apparatus and for survey stations to be sampled within the needed timeline. Further, vessel owners were responsible for all costs associated with vessel use and were compensated through an allocation of scallop pounds awarded by the National Oceanic and Atmospheric Administration through the Atlantic Scallop Research Set-Aside Program ${ }^{29}$. Though it is not necessary to engage industry in surveys, the size, capabilities, and costs of available vessels must be considered before developing other aspects of the survey design.

The data collection and processing aspects of the protocols present the greatest advantage, but also a limitation of this method. The use of custom software and databases to quantify data within images comes at a substantial cost. However, the use of these products by the SMAST drop camera survey represents an evolution of a program started in 1999 and is not essential. For example, when the program first started, scallop counts were made with pen and paper and free software is now available to measure within images. Similarly, the current digital still camera was chosen as it was capable of detecting all size classes of scallops and allowed for approximately $200 \%$ magnification without loss of image quality (Figure 3), but lower resolution, less expensive cameras used earlier in the survey were able to fully detect scallops of commercial $\mathrm{size}^{30}$. As with the survey design protocols, the type of camera should be linked to the resolution needed to detect the target species and achieve survey goals. Capturing images and recording video at each station provides a significant advantage over traditional survey methods by providing the continuous ability to revisit samples and expand the analysis to taxa or habitat characteristics not initially tracked or enumerated. For example, images with sand dollars and other echinoderms originally noted as present or absent in the SMAST database were revisited to quantify their abundance and biomass through time ${ }^{12}$. In contrast, samples from more traditional survey methods such as dredges or nets are discarded at-sea and cannot be revisited. However, the advances that allow for massive amounts of images to be taken and stored can result in millions of images being collected with only a small fraction being utilized. This is largely due to time and cost restrictions as humans are needed for data extraction and result in large amounts of unutilized information ${ }^{31}$. Advances in automated detection of animals and habitat characteristics may help to address this conundrum.

Image based survey methods can provide the necessary data to monitor macroinvertebrates and associated habitat, but supplementing the protocols described here with other methods that collect biological samples is ideal. Without a scallop shell-height meat weight relationship, created from dredge-based sampling, biomass estimates would not be possible. Further, the scallop shell-height meat weight relationship varies with time and location on Georges Bank indicating that consistently updating the equation used to describe this relationship is beneficial ${ }^{32}$. Combining image and physical sample-based techniques also aids in exploring the biases and assumptions of each method. Measuring shell heights of scallops in drop camera images with calipers quantified a measurement bias associated with the curvature of the camera lens and distance from the image center ${ }^{33}$. Conversely, paired comparisons between images and dredge tows have helped define what proportion of scallops on the sea floor are actually collected and how the proportion changes with scallop size ${ }^{6}$.

Underwater imaging has been used in the field of marine ecology for decades ${ }^{17,34}$. However, decreasing costs of high-resolution cameras and data storage have made the approach more practical than in the past. The methods described in this paper can be generalized and have broad applicability, helping to facilitate the development of more image-based surveys. More specifically, the procedures show how results can be used to produce data to help manage sessile invertebrates (Tables 1-2) and contribute to a broader understanding of the marine environment ${ }^{7,9,10,11,12,13,14,15}$.

\section{Disclosures}

The authors have nothing to disclose.

\section{Acknowledgements}

Thanks to the students, staff, captains, and crews who sailed on these research trips and owners that provided their vessels. Thanks to T. Jaffarian for developing the lab data collection program, Electromechanica, Inc. for developing the field software and equipment, and to CVision Consulting for developing the Image annotator program. Funding was provided by NOAA awards NA17NMF4540043, NA17NMF4540034, and NA17NMF4540028. The views expressed herein are those of the authors and do not necessarily reflect the views of the NOAA.

1. Stokesbury, K.D.E., O'Keefe, C.E., Harris, B.P. Fisheries Sea Scallop, Placopecten magellanicus. In: Shumway S, Parsons GJ, editors. Scallops: Biology, Ecology, Aquaculture, and Fisheries 3rd ed. Elsevier B.V. Amsterdam. (2016)

2. NMFS (National Marine Fisheries Service). Fisheries Economics of the United States, 2015. U.S. Dept. of Commerce, NOAA Tech Memo. NMFS-F/SPO-170 (2017).

3. Stokesbury, K.D.E., and Himmelman, J.H. Spatial distribution of the giant scallop Placopecten magellanicus in unharvested beds in the Baie des Chaleurs, Québec. Mar. Ecol. Prog. Ser. 96, 159-168 (1993).

4. Stokesbury, K.D.E., and Himmelman, J.H. Examination of orientation of the giant scallop, Placopecten magellanicus, in natural habitats. Can. J. Zool. 73, 1945-1950 (1995).

5. Stokesbury, K.D.E., Harris, B.P., Marino II, M.C., Nogueira, J.I. Estimation of sea scallop abundance using a video survey in off-shore USA waters. J. Shellfish Res. 23, 33-44 (2004).

6. Malloy Jr, R., Bethoney, N.D., Stokesbury, K.D.E. Applying dredge and optical methods to compare sediment classification and size frequency of the sea scallop (Placopecten magellanicus). J. Shellfish Res. 34 (2), 657 (2015). 
7. Bethoney, N.D., Zhao, L., Chen, C., Stokesbury, K.D.E. Identification of persistent benthic assemblages in areas with different temperature variability patterns through broad-scale mapping. PLoS ONE. 12 (5), e0177333. <https://doi.org/10.1371/journal.pone.0177333> (2017).

8. NEFSC (Northeast Fisheries Science Center). Stock assessment for Atlantic sea scallops in 2014. In: 59th Northeast Regional Stock Assessment Workshop (59th SAW) Assessment Report. U.S. Dept. of Commerce, NEFSC Ref. Doc. 14-09 (2010).

9. MacDonald, A.M., Adams, C.F., Stokesbury, K.D.E. Abundance estimates of skates (Rajidae) on the continental shelf of the northeastern USA using a video survey. Trans. Am. Fish. Soc. 139, 1415-1420 (2010).

10. Marino II, M.C., Juanes, F., Stokesbury, K.D.E. Effect of closed areas on populations of sea star Asterias spp. On Georges Bank. Mar. Ecol. Prog. Ser. 347, 39-49 (2007).

11. Marino II, M.C., Juanes, F., Stokesbury, K.D.E. Spatio-temporal variations of sea star Asterias spp. distributions between sea scallop Placopecten magellanicus beds on Georges Bank. Mar. Ecol. Prog. Ser. 382, 59-68 (2009).

12. Rosellon-Druker, J. Describing echinoderm (Echinodermata) populations on Georges Bank and evaluating direct and indirect effects of marine protected areas on these populations. Ph.D thesis. University of Massachusetts Dartmouth (2016).

13. Stokesbury, K.D.E., and Harris, B.P. Impact of limited short-term sea scallop fishery on epibenthic community of Georges Bank closed areas. Mar. Ecol. Prog. Ser. 307, 85-100 (2006).

14. Harris, B.P., and Stokesbury, K.D.E. The spatial structure of local surficial sediment characteristics on Georges Bank, USA. Cont. Shelf. Res. 30, 1840-1853 (2010)

15. Harris, B.P., Cowles, G.W., Stokesbury, K.D.E. Surficial sediment stability on Georges Bank in the Great South Channel and on eastern Nantucket Shoals. Cont. Shelf. Res. 49, 65-72 (2012).

16. Anderson, S.C., Mills-Flemming, J., Watson, R., Lotze, H.K. Rapid Global Expansion of Invertebrate Fisheries: Trends, Drivers, and Ecosystem Effects. PLoS ONE. 6 (3), e14735. (2011).

17. Murphy, H.M., and Jenkins, G.P. Observational methods used in marine spatial monitoring of fishes and associated habitats: A review. Mar. Freshw. Res. 61, 236-252 (2010).

18. Monk, J. How long should we ignore imperfect detection of species in the marine environment when modelling their distribution? Fish. Fish. 15, 352-358 (2014).

19. O'Keefe, C.E., Carey, J.D., Jacobson, L.D., Hart, D.R., Stokesbury, K.D.E. Comparison of scallop density estimates using the SMAST scallop video survey data with a reduced view field and reduced counts of individuals per image. Appendix 3. In: 50th Northeast Regional Stock Assessment Workshop (50 ${ }^{\text {th }}$ SAW) Assessment Report. U.S. Dept. of Commerce, NEFSC Ref. Doc. 10-17 (2010).

20. Cochran, W. G. Sampling Techniques. 3rd ed. John Wiley \& Sons. New York (1977).

21. NEFMC. Final Framework 28 to the Atlantic Sea Scallop Fishery Management Plan with Environmental Assessment, Regulatory Impact Review, and Regulatory Flexibility Analysis. Newburyport, MA. Available: <http://www.nefmc.org/scallops/index.html> (2017).

22. Yochum, N., DuPaul, W.D. Size-selectivity of the northwest Atlantic sea scallop (Placopecten magellanicus) dredge. J. Shellfish Res. 27, 265-271 (2008).

23. Brand, A.R. Scallop ecology: distributions and behaviour. In: Shumway S editor. Scallops: biology, ecology and aquaculture. Elsevier B.V. Amsterdam. (1991).

24. Krebs, C. J. Ecological Methodology. Harper \& Row Publishers Inc. New York (1989).

25. Stokesbury, K.D.E. Estimation of sea scallop, Placopecten magellanicus, abundance in closed areas of Georges Bank. Trans. Am. Fish. Soc. 131, 1081-1092 (2002).

26. Adams, C.F., Harris, B.P., Stokesbury, K.D.E. Geostatistical comparison of two independent video surveys of sea scallop abundance in the Elephant Trunk Closed Area, USA. ICES J Mar Sci. 65, 995-1003 (2008).

27. NEFMC. Final Framework 27 to the Atlantic Sea Scallop Fishery Management Plan with Environmental Assessment, Regulatory Impact Review, and Regulatory Flexibility Analysis. Newburyport, MA. Available: <http://www.nefmc.org/scallops/index.html> (2016).

28. CIE (Center for Independent Experts). Individual Peer Review Report. Review of Sea Scallop Survey Methodologies and their Integration for Stock Assessment and Fishery Management. New England Fisheries Science Center Scallop Survey Methods Peer Review Meeting 17-19 March 2015, New Bedford, MA. (2015).

29. NOAA (National Oceanic and Atmospheric Administration). Research Set-Aside Program [cited 2017 10/25]. Available from: <https:// www.nefsc.noaa.gov/coopresearch/rsa_program.html> (2017).

30. Marino II, M.C., O'Keefe, C.E., Jacobson, L.D. Selectivity and efficiency of large camera video data from the SMAST video survey during 2003 - 2006: Appendix B7. In: 45th Northeast Regional Stock Assessment Workshop (45 ${ }^{\text {th }}$ SAW) Assessment Report. U.S. Dept. of Commerce, NEFSC Ref. Doc. 07-16 (2007).

31. Chang, J., Hart, D.R., Shank, B.V., Gallagher, S.M., Honig, P., York, A.D. Combining imperfect automated annotations of underwater images with human annotations to obtain precise and unbiased population estimates. Methods Oceanogr. 17, 169-186 (2016).

32. Hennen, D.R., and Hart, D.R. Shell height-to-weight relationships for Atlantic sea scallops (Placopecten magellanicus) in offshore U.S. waters. J. Shellfish Res. 31 (4), 1133-1144 (2012).

33. Jacobson, L.D. et. al. Measurement errors in body size of sea scallops (Placopecten magellanicus) and their effect on stock assessment models. Fish. Bull. 108, 233-247 (2010).

34. Mallet, D., and Pelletier, D. Underwater video techniques for observing coastal marine biodiversity: A review of sixy years of publications (1952-2012). Fish. Res. 154, 44-62 (2014). 